\title{
Dental Student's Attitudes on the Effectiveness of Mock Employment Interviews
}

\author{
Lillian Obucina $^{1^{*}}$, Pamela Jurgens-Toepke ${ }^{2}$, Jacob Gettig ${ }^{3}$, Kevin Van Kanegan ${ }^{4}$ \\ ${ }^{1}$ Assistant professor at Midwestern University College of Dental Medicine-Illinois, US \\ ${ }^{2}$ Assistant professor at Midwestern University College of Dental Medicine-Illinois, US \\ ${ }^{3}$ Associate Dean for Postgraduate Education at Midwestern University College of Pharmacy Illinois, US \\ ${ }^{4}$ Assistant professor at Midwestern University College of Dental Medicine-Illinois, US
}

*Corresponding Author: Lillian Obucina, Assistant professor at Midwestern University College of Dental Medicine-Illinois, US

\begin{abstract}
Very little research exists regarding mock interviews to help dental students prepare for associate dentist employment interviews. Midwestern University, College of Dental Medicine-Illinois (MWU-CDMI-IL) constructed and conducted mock interviews for each senior dental student. Faculty were calibrated prior to the mock interviews. Students were interviewed by two unfamiliar faculty members, acting as owners of a fictitious dental practice. Each performance was evaluated by the two faculty members, student selfevaluations and student peers that just completed their interviews. The number of peer reviewers varied depending on the scheduled interviews. Feedback was given immediately after the mock interview from the faculty and peer reviewers. A survey was conducted asking the dental students about their attitudes and the effectiveness of their mock employment interviews. The responses showed the mock interviews were well received by the students.
\end{abstract}

\section{Educational Objectives}

By the end of this session, learners will be able to:

1. Develop professional interview presence, etiquette and responses to employer questions

2. Analyze the practice philosophy, ethics, business structure and billing policies of a fictitious practice

3. Demonstrate appropriate behaviors and communications in a simulated job interview

4. Judge the appropriateness and legality of interview questions and decide how to respond appropriately Apply interviewing techniques and strategies when interviewing for an associate dental position

\section{INTRODUCTION}

Graduating dental students historically, have not received interview training. MWU-CDMI-IL recognized the need to not only prepare dental students for patient care, but also in practice management. Interviewing for a prospective dental position or post graduate program can be intimidating. It is imperative that students are prepared for their future interviews. The college's goal is to have all students get accepted into a post graduate program or associate position of their choice. Thus, this session was created to address the need for preparation through simulated practice.

As part of their practice management curriculum, fourth year dental students will engage in a mock interview prior to interviewing for a post graduate position or associate position. The development of the mock interview protocol can be utilized by all health professions education programs. The target audience will be students that are completing their clinical programs within the next twelve months. The prerequisites needed are investigation of a fictitious practice, development of a curriculum vitae, cover letter and a thank you note.

Very few articles regarding mock interviews for dental students are available. Everett-Gutmann (1988) conducted mock interviews for dental hygiene students. They found that the students initially 
did not take the mock interviews seriously ${ }^{1}$. When the day arrived for the interview, the students were nervous and treated the mock interview as if it was real. ${ }^{1}$

\section{METHODS}

Students and faculty were given two lectures: 1. developing a curriculum vitae (CV), cover letter and thank you note, and 2. interviewing etiquette, appropriate interview questions and illegal interview questions. Students were told that they would be interviewing for an associate position with a fictitious Dr. Smiley. They were given information regarding Dr. Smiley, his office and the associate position. Faculty were calibrated during a one-hour session to be the interviewer, Dr. Smiley. During the calibration session, faculty were briefed on Dr. Smiley's office protocol and demographics. Faculty read the job description and were encouraged to ask questions about their role as interviewer. They were given sample interview questions and instructed to ask some inappropriate questions such as: "Are you married? "Do you have children? and "What religion are you?"

A total of 123 fourth year dental students and 24 full-time clinical faculty participated in the mock interviews. On average, faculty members spent two hours preparing for the mock interviews and six hours participating in the mock interviews. Additionally, seven rooms were reserved to serve as interview sites. Two faculty and the course coordinators, acted in an oversight capacity to ensure the simulation went smoothly and to act as a resource for students and faculty, if needed.

A fictitious dental practice was developed by combining elements from various dental office websites. An associate dentist job posting was obtained from the Chicago Dental Society Review journal. This specific posting was chosen because it offered a full-time position, open to recent graduates, at a very high rate of compensation. The investigator's approach was to present the students with an attractive offer, but then bring out other information that would test the students' ethics and practice philosophy to see how they would tackle some potentially difficult realities e.g. on-call every weekend, extractions, endodontics, travel between offices.

The students were shown attractive office photos. The main page of the fictitious website shows that the office is open 47 hours per week, including Saturdays, and that "many insurance plans are accepted including PPO and HMO plans. The practice demographics are average for a mid-sized suburban location. Dr. Smiley has a history of a licensure reprimand, albeit over 20 years ago, for "poor and inadequate maintenance of records of treatment resulting in insurance billings submitted for services not rendered."

Further in the website, there is information regarding some of the procedures performed by Dr. Smiley with statements such as they prefer to replace "silver/mercury" fillings with tooth-colored resin, and "white fillings are healthier because no traces of mercury are used."

Dr. Smiley's blog offers statements by him that the office staff has "extreme pressure to get all the little things right. I have monthly meetings with my staff at our three offices, and truth be told, they probably look at me like I'm a looney...I hope and pray my staff and patients get a sense that this is what I'm after when I go crazy town with my requests, expectations and routines."

The students were also exposed to the practice's social media postings of a free dental day and "Shark Week ${ }^{\mathrm{TM}}$ " humor. Also, in the social media arena, Dr. Smiley's office promotions credit patient's account ledgers for giving Facebook ${ }^{\mathrm{TM}}$ "Likes" and patient referrals. Office Yelp ${ }^{\mathrm{TM}}$ reviews are mixed showing a rushed office atmosphere and at least one presumably rude front office staff member.

The mock interviews were conducted in small conference rooms. Two faculty members interviewed each student. Two faculty were chosen intentionally. Faculty have varied experiences with interviewing staff members. Their combined business acumen added to the interview process. They both called themselves Dr. Smiley. The student was instructed to bring their CV, cover letter and a thank you note to the interview. Faculty interviewed six students at each session. Each interview lasted 20 minutes. Faculty and students were dressed appropriately for the interview.

The student was instructed to enter the interview room and shake hands with each Dr. Smiley. Faculty initially evaluated the student's eye contact, body language and professional attire. Once seated, the faculty had a list of sample questions that they asked each candidate. They were allowed to improvise their questions as the interview proceeded. Faculty were prompted to ask inappropriate or illegal questions such as "Do you have children? What is your religion? Are you pregnant or planning on getting pregnant?" 
Once the student was done with their mock interview, they stayed in the interview room. The faculty proceeded to fill out a mock interview assessment rubric. The student that completed their interview would fill out a student self-evaluation assessment and then remain in the mock interview room and become a peer reviewer. They would complete a Peer Mock Interview Assessment rubric for each interview that they witnessed as a peer reviewer. These were reviewed during the debriefing after each interview and then given to the interviewee. The feedback and assessments from faculty and peers was used as a formative and summative assessment. Student were graded on their performance. Faculty and students (self-evaluation) also assessed the CV's and cover letter. They received a pass/fail grade. This process continued until all of the students completed their mock interviews.

At the conclusion of the mock interviews, faculty and students debriefed on each student interview. Students were given positive and negative feedback regarding their appearance, body language, ability to answer interview questions, and preparedness for the interview e.g., thorough understanding of the position and Dr. Smiley's office, CV, cover letter, thank you note, and their posed questions.

\section{RESULTS}

Approximately 5 months after the mock interviews, students were invited to participate in a voluntary survey about the perceived benefits of the exercise and the numbers of actual interviews and offers they had received. The survey items 1 through 11 asked about perceived benefits of the exercise, and were scored on a 6-point Likert scale $(6=$ Strongly Agree, $5=$ Agree, $4=$ Tend to Agree, $3=$ Tend to Disagree, $2=$ Disagree, $1=$ Strongly Disagree). Items 12 to 16 in the survey asked students about whether they received offers to interview for employment and/or residencies before and/or after the mock interview experiences and, if so, how many interview offers for each. In addition, one item asked how many interviews students had completed before receiving their first job offer.

A total of 87/123 (70.7\%) students completed the survey. The mean age of respondents was 28 with a slight majority (56.8\%) of respondents being male (Table 1 ).

Table1. Demographics

\begin{tabular}{|l|l|l|}
\hline \multicolumn{1}{|c|}{ Age, Mean (SD) $\mathbf{N}=\mathbf{8 1}^{\mathbf{a}}$} & \multicolumn{2}{|c|}{$\mathbf{2 8 . 0}(3)$} \\
\hline \multirow{2}{*}{ Gender, $\mathbf{N}=\mathbf{8 1}^{\mathbf{b}}$} & No. Female (\% Female) & $33(40.7)$ \\
\cline { 2 - 3 } & No. Male (\% Male) & $46(56.8)$ \\
\hline
\end{tabular}

a 7 respondents chose "prefer not to respond", thus denominator for mean is 74

b 2 respondents chose "prefer not to respond"

Median responses to 11 items that started with the stem "The DENTD 1821 mock employment interviews were valuable in helping me..." was "Agree" for 9/11 of the items and "Tend to Agree" for the remaining 2/11 items. The item with the highest level of agreement (median 5=agree, mean 4.98) was "...formulate questions I want to ask my potential employer". The item with the lowest level of agreement (median $4=$ tend to agree, mean 4.01) was "... reduce the anxiety I feel during interviews". Other details about the survey responses to items 1 to 11 are summarized in Table 2.

Table2. Survey Responses

\begin{tabular}{|l|l|l|l|}
\hline $\begin{array}{l}\text { “The DENTD 1821 mock employment interviews were valuable } \\
\text { in helping me ..." }\end{array}$ & $\begin{array}{c}\text { No. } \\
\text { Responses }\end{array}$ & $\begin{array}{c}\text { Median } \\
\text { Response } \\
\text { (IQR) }\end{array}$ & $\begin{array}{c}\text { Mean } \\
\text { Response } \\
\text { (SD) }\end{array}$ \\
\hline Anticipate likely employer questions and how to reply to them. & 87 & $5(4-5)$ & $4.53(1.0)$ \\
\hline $\begin{array}{l}\text { Recognize inappropriate and/or illegal employer questions and how } \\
\text { to reply to them. }\end{array}$ & 87 & $5(4-5)$ & $4.78(1.0)$ \\
\hline Formulate questions I want to ask my potential employer. & 87 & $5(4-6)$ & $4.98(1.0)$ \\
\hline Investigate a dental practice's demographic data. & 86 & $4(4-5)$ & $4.53(1.0)$ \\
\hline Investigate a dental practice's philosophy. & 87 & $5(4-5)$ & $4.56(1.0)$ \\
\hline Investigate a dental practice's social media presence. & 85 & $5(4-5)$ & $4.52(1.0)$ \\
\hline Reduce the anxiety I feel during interviews. & 86 & $4(3-5)$ & $4.01(1.2)$ \\
\hline Be more aware of my non-verbal body language. & 86 & $5(4-5)$ & $4.48(1.1)$ \\
\hline $\begin{array}{l}\text { Choose appropriate items to create a professional appearance e.g. } \\
\text { attire, notepad, business card }\end{array}$ & 87 & $5(4-5)$ & $4.68(1.1)$ \\
\hline $\begin{array}{l}\text { Self-assess my overall preparedness for an actual employment } \\
\text { interview for an associate dentist employment position }\end{array}$ & 85 & $5(4-5)$ & $4.62(1.1)$ \\
\hline $\begin{array}{l}\text { Self-assess my overall preparedness for an interview for a post } \\
\text { graduate, AEGD or GPR residency program position }\end{array}$ & 84 & $5(3-5)$ & $4.24(1.3)$ \\
\hline
\end{tabular}

*bolded items indicate a significant difference between one or more groupings of responses 
A total of $19(25.7 \%)$ and $46(61.2 \%)$ of respondents had received interview offers for practice positions or employment before and after the mock interviews, respectively. The average number of interview offers for practice positions was 2.2, and the average number of interviews completed prior to first job offer was 1.6. In addition, $21(30.4 \%)$ and $16(23.2 \%)$ of respondents had received interview offers for residencies before and after the mock interviews, respectively. The average number of interview offers for residencies was 3.3. Other details about responses to items 12 to 16 are summarized in Table 3.

Table3. Interviews

\begin{tabular}{|c|c|}
\hline $\begin{array}{l}\text { Number of students that received offers for employment interviews before mock interview (of } 74 \\
\text { valid responses) } \mathrm{N}(\%)\end{array}$ & $\begin{array}{l}19 \\
(25.7)\end{array}$ \\
\hline $\begin{array}{l}\text { Number of students that received offers for employment interviews after mock interview (of } 74 \\
\text { valid responses) } \mathrm{N}(\%)\end{array}$ & $\begin{array}{l}46 \\
(61.2)\end{array}$ \\
\hline Average number of employment interviews received (of 52 valid responses) Mean (SD) & $\begin{array}{l}2.2 \\
(1.8)\end{array}$ \\
\hline $\begin{array}{l}\text { Average number of employment interviews before first job offer (of } 49 \text { valid responses) } \\
\text { Mean (SD) }\end{array}$ & $\begin{array}{l}1.6 \\
(1.7)\end{array}$ \\
\hline $\begin{array}{l}\text { Number of students that received offers for residency interviews before mock interview (of } 69 \text { valid } \\
\text { responses) } \mathrm{N}(\%)\end{array}$ & $\begin{array}{l}21 \\
(30.4)\end{array}$ \\
\hline $\begin{array}{l}\text { Number of students that received offers for residency interviews after mock interview (of } 69 \text { valid } \\
\text { responses) } \mathrm{N}(\%)\end{array}$ & $\begin{array}{l}16 \\
(23.2)\end{array}$ \\
\hline $\begin{array}{l}\text { Average number of residency interviews received (of } 29 \text { valid responses) } \\
\text { Mean (SD) }\end{array}$ & $\begin{array}{l}3.3 \\
(3.1)\end{array}$ \\
\hline
\end{tabular}

The overall response rate was $70.7 \%$. The responses showed the mock interviews were well received by the students. Statistical differences $(\mathrm{p}<0.05)$ were found in Questions 1, 2, 5, 6, 8, 9 and 11. There were no statistically significant differences found between students who received interviews and those that did not receive interviews at the time of survey administration. There were no statistically significant differences found between males and females, or for older (above 28 years of age) versus younger (less than or equal to 28 years of age) students relative to the number of interviews they received.

\section{DISCUSSION}

The mock interviews were well received by the students. Similar to Everett-Gutmann's (1988) findings, students and faculty both took the interviews very seriously when the day arrived. The students found the interviews especially effective in preparing them to formulate questions for their future employer, recognizing inappropriate and illegal interview questions, and improving their professional appearance.

A single one hour, faculty calibration was sufficient to prepare faculty to interview the students. They were well informed about their fictitious practice, including the expectations they had for the new associate dentist they were hiring. Faculty business acumen also contributed to ad lib questions that complimented the information they were given during the calibration session. Some additional questions the faculty asked the students included questions pertaining to the breadth of patient care experiences they performed while in school, prior exposure and competency with dental technology, and their current efficiency in completing particular procedures. Some students were asked how many teeth they could extract in an hour, whether they could manage a schedule of 30 patients per day, and whether they would mind travelling between numerous office locations from day to day. Twenty minute interviews seemed appropriate in length and allowed enough time for interactive faculty questions, student responses, and for students to initiate questions of their own. Familiarity of dental faculty, even though not currently assigned to the students in their clinical suites, and the fact that this was a simulated interview, reduced some of the real stress that an interviewee would normally feel.

Midwestern University College of Dental Medicine - Illinois just completed another round of mock interviews for the Class of 2018.Two modifications to this current format were implemented. The Class of 2018 had students interview each other during mock interviews, instead of having faculty interviewing the students. This change was decided because of the intense faculty resources that were used in the current protocol. Another change was to not have the students dress professionally for the interview. Due to a scheduling change of when this class is being taught, relative to when the students 
perform patient care, it was felt that the students would not have enough time to change into clinical scrubs after the interviews were completed, to be ready in time for patient care.

It will be interesting to see if the student's lack of business experience will make the interview questions they ask less probing, surprising or effective. Also, it will be interesting to see if the student's familiarity with each other will make the interviews seem less serious. Finally, we will evaluate what impact not dressing professionally, will have on the student's attitudes.

\section{CONCLuSiON}

The mock interviews were relatively simple to set up. Time was needed to calibrate the faculty prior to the interviews. It would be useful to show a video of past mock interviews to faculty, so that they can gauge how much interaction is needed as well as how to assess student responses. Due to the success of this process, mock interviews will continue to be conducted in the fourth year of dental school. A subsequent survey will be conducted at the conclusion of mock interviews this academic year to compare the different formats.

\section{REFERENCE}

[1] Everett-Gutmann, M. Perceived value of mock interviews as preparation for seeking employment. Journal of Dental Education. 1988; 10:571-573.

\section{AUTHOR's BIOGRAPHY}

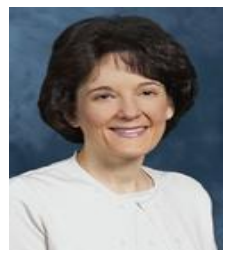

Lillian Obucina, is an Assistant Professor at Midwestern University College of Dental Medicine-Illinois. She has a Doctor of Dental Surgery degree with a specialty in Prosthodontics as well as a Juris Doctorate degree.

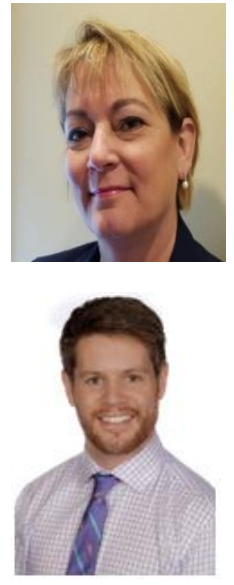

Pamela Jurgens-Toepke, is an Assistant Professor at Midwestern University College of Dental Medicine-Illinois. She has a Doctor of Dental Surgery degree as well as a Master of Arts in Educational Administration, Adult and Higher Education.

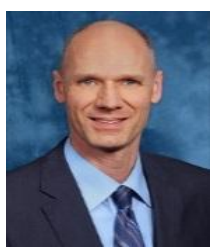

Jacob Gettig, is Associate Dean for Postgraduate Education and Professor of Pharmacy Practice at Midwestern University Chicago College of Pharmacy. He has a Doctor of Pharmacy degree and has master's degrees in Public Health and Education. $\mathrm{He}$ is board certified in pharmacotherapy and is a certified healthcare CPD (continuing professional development) professional.

Kevin Van Kanegan, is an Assistant Professor at Midwestern University College of Dental Medicine-Illinois. He has a Doctor of Dental Surgery Degree as well as a Master in Health Professions Education.

Citation: Lillian Obucina, Pamela Jurgens-Toepke, Jacob Gettig, Kevin Van Kanegan. "Dental Student's Attitudes on the Effectiveness of Mock Employment Interviews". International Journal of Humanities Social Sciences and Education (IJHSSE), vol 5, no. 1, 2018, pp. 112-116. doi: http://dx.doi.org/10.20431/2349-0381. 0501017.

Copyright: (1) 2018 Authors. This is an open-access article distributed under the terms of the Creative Commons Attribution License, which permits unrestricted use, distribution, and reproduction in any medium, provided the original author and source are credited. 